\title{
A Case of Elevation of Serum Creatine Kinase With Antithyroid Medications for Graves' Disease
}

\author{
Tatsuo Ito ${ }^{\mathrm{a}}$, Masahito Katahira, ${ }^{\mathrm{a}, \mathrm{b}}$, Mizuki Hanakita ${ }^{\mathrm{a}}$, Mari Suzuki ${ }^{\mathrm{a}}$
}

\begin{abstract}
We describe a female patient with Graves' disease (GD) who had abnormal increases of serum creatine kinase (CK) concentration during treatment with antithyroid medications. She experienced myalgia and manifested increased serum CK levels, with a maximum of 7,925 U/L, 2 - 4 months after initiation of methimazole (MMI) treatment at a dose of $10-15 \mathrm{mg} /$ day. After MMI was exchanged for potassium iodide (KI), serum CK levels decreased and the myalgia resolved. However, after KI was exchanged for propylthiouracil (PTU), the myalgia recurred and serum CK levels increased with a maximum of $521 \mathrm{U} / \mathrm{L}$. PTU was discontinued and serum CK levels returned to normal, but hyperthyroidism recurred and the patient did not consent to the alteration of treatment from antithyroid drugs to radioiodine therapy or surgical treatment. PTU was restarted and increased gradually from 50 to $300 \mathrm{mg} /$ day. Serum CK levels did not increase, but the hyperthyroidism persisted. After we exchanged PTU for MMI (20 mg/day) and levothyroxine ( $25 \mu \mathrm{g} /$ day), serum CK levels did not increase and the hyperthyroidism diminished. While the mechanisms for this process are not clearly defined, a rapid reduction in thyroid hormones in tissues following chronic hyperthyroidism may result in relative hypothyroid states and subsequent alterations in CK concentration.
\end{abstract}

Keywords: Creatine kinase; Levothyroxine; Methimazole; Propylthiouracil; Side effect

\section{Introduction}

Antithyroid drugs such as methimazole (MMI) and propylthiouracil (PTU) are generally effective in the therapy of

\footnotetext{
Manuscript accepted for publication December 13, 2012

${ }^{a}$ Department of Endocrinology and Diabetes, Ichinomiya Municipal Hospital, Aichi 491-8558, Japan

${ }^{\mathrm{b} C o r r e s p o n d i n g ~ a u t h o r: ~ M a s a h i t o ~ K a t a h i r a, ~ D e p a r t m e n t ~ o f ~}$ Endocrinology and Diabetes, Ichinomiya Municipal Hospital, 2-2-22 Ichinomiya, Aichi 491-8558, Japan. Email: katahira-0034@umin.net
}

doi: http://dx.doi.org/10.4021/jem130w
Graves' disease (GD), but may be associated with adverse events. These include skin reactions, arthralgias, and gastrointestinal effects, as well as more serious complications such as agranulocytosis, polyarthritis, and immunoallergic hepatitis [1].

Creatine kinase (CK) is a muscle-specific kinase, and measurement of serum concentration of CK is a useful indicator of muscle breakdown. Although the mechanisms are unknown, CK levels are high in patients with hypothyroidism [2]. While several case reports describe elevations of serum $\mathrm{CK}$ and myalgia in patients undergoing treatment of GD with antithyroid drugs [3-9], this adverse effect is relatively rare. Here, we report a case of elevated serum CK levels, without evidence of a hypothyroid state, in a patient with GD who was treated with antithyroid medications. As mentioned in previous reports $[3,5-8]$, a rapid reduction in thyroid hormone might have caused the increased serum concentrations of CK and muscle symptoms in this patient.

\section{Case Report}

A 43-year-old woman presented with a history of weight gain $(10 \mathrm{~kg})$ over the past months and was admitted to the Department of Cardiology of our hospital on March 29, 2010, because of heart palpitations and leg edema that had appeared a few weeks previously. Blood sampling revealed thyrotoxicosis, which prompted consultation of our department. Her past and family histories were unremarkable.

Physical examination revealed the following findings: height, $165 \mathrm{~cm}$; weight, $66.2 \mathrm{~kg}$; blood pressure, 152/78 $\mathrm{mmHg}$; pulse rate, 128 beats/min and irregular; and temperature, $36.8{ }^{\circ} \mathrm{C}$. Oxygen saturation was $97 \%$ in ambient air. A nonpainful diffuse goiter without palpable nodules was present. Heart sounds were irregular with a systolic murmur auscultated at the apex and at the tricuspidal point. There was dullness at the base of the right lung and decreased breath sounds. There were no signs of hepatomegaly. Moderate pitting edema was detected in the legs with no signs of deep vein thrombosis.

Laboratory evaluation revealed the following: white blood cell count, 4,700/mL; hemoglobin, $11.9 \mathrm{~g} / \mathrm{dL}$; gly- 

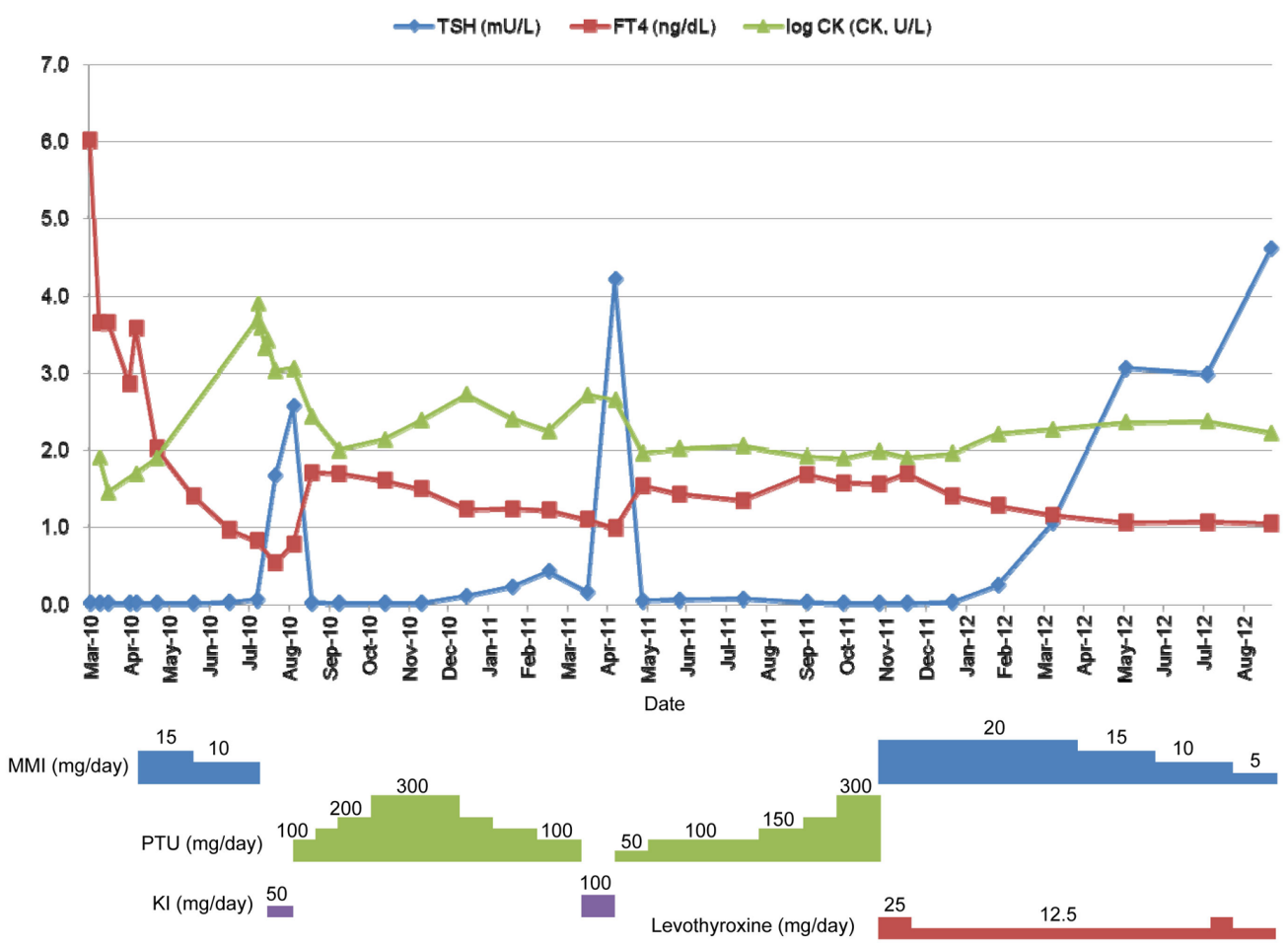

Figure 1. Serum concentrations of TSH and FT4 together with the common logarithms of the CK level (log CK).

cemia, $119 \mathrm{mg} / \mathrm{dL}$; sodium, $138 \mathrm{mEq} / \mathrm{L}$; potassium, 3.7 $\mathrm{mEq} / \mathrm{L}$; chloride, $107 \mathrm{mEq} / \mathrm{L}$; blood urea nitrogen, $10.9 \mathrm{mg} /$ $\mathrm{dL}$; creatinine, $0.42 \mathrm{mg} / \mathrm{dL}$; albumin, $3.3 \mathrm{~g} / \mathrm{dL}$; and calcium, $8.2 \mathrm{mg} / \mathrm{dL}$. Aspartate aminotransferase and alanine aminotransferase were $33 \mathrm{U} / \mathrm{L}$ and $21 \mathrm{U} / \mathrm{L}$, respectively. Alkaline phosphatase, lactate dehydrogenase, and creatine kinase (CK) levels were elevated to $501 \mathrm{U} / \mathrm{L}$ (normal, 115 - 359 U/L), $258 \mathrm{U} / \mathrm{L}$ (normal, 119 - $229 \mathrm{U} / \mathrm{L}$ ), and $396 \mathrm{U} / \mathrm{L}$ (normal $45-163 \mathrm{U} / \mathrm{L}$ ), respectively. The level of total cholesterol was decreased to $89 \mathrm{mg} / \mathrm{dL}$ (normal, $128-219 \mathrm{mg} / \mathrm{dL}$ ). Thyroid function tests confirmed a state of thyrotoxicosis with a TSH level of $<0.01 \mathrm{mU} / \mathrm{L}$ (normal, $0.49-4.94 \mathrm{mU} / \mathrm{L}$ ), a free triiodothyronine (FT3) level of $9.57 \mathrm{pg} / \mathrm{mL}$ (normal, 1.71 - 3.71 $\mathrm{pg} / \mathrm{mL}$ ), and a free thyroxine (FT4) level of $>6.00 \mathrm{ng} / \mathrm{dL}$ (normal, $0.70-1.48 \mathrm{ng} / \mathrm{dL}$ ). The levels of thyroglobulin antibody, thyroid peroxidase antibody, TSH receptor antibody (TRAb), and thyroid stimulating antibody (TSAb) were 1.1 $\mathrm{U} / \mathrm{mL}$ (normal, $<0.3 \mathrm{U} / \mathrm{mL}$ ), $15.5 \mathrm{U} / \mathrm{mL}$ (normal, $<0.3 \mathrm{U} /$ $\mathrm{mL}$ ), $7.6 \mathrm{U} / \mathrm{mL}$ (normal, $<1.0 \mathrm{U} / \mathrm{mL}$ ), and 142\% (normal, < $180 \%$ ), respectively. The remaining laboratory results were within normal range.

Electrocardiography showed rapid atrial fibrillation at a ventricular rate of 132 beats/min. Thoracic radiography showed bilateral pleural effusion that was more pronounced on the right-hand side. Echocardiography revealed decreased ejection fraction $(30 \%)$, left ventricular systolic dysfunction, and moderate mitral and tricuspid regurgitations. The condition was diagnosed as heart failure and atrial fibrillation due to thyrotoxicosis. The patient was treated with diuretics, $\beta$-blockers (metoprolol), and anticoagulants such as heparin and warfarin. Sinus rhythm was achieved and repeat chest radiography on April 15, 2010, revealed normal heart size and no pleural effusion.

Although the levels of FT3, FT4, and CK on April 5, 2010 , were decreased to $5.38 \mathrm{pg} / \mathrm{mL}, 3.64 \mathrm{ng} / \mathrm{dL}$, and 81 $\mathrm{U} / \mathrm{L}$, respectively, without antithyroid therapy, on April 12, FT3 level had increased to $21.54 \mathrm{pg} / \mathrm{mL}$, FT4 level remained unchanged, and technetium- $99 \mathrm{~m}$ uptake was high $(21.23 \%$; normal, $0.4-3.0 \%$ ). From these findings, the disease was diagnosed as thyrotoxicosis due to GD and administration of MMI (15 mg/day) was initiated on April 16, 2010.

Although the TSH level remained suppressed below $0.01 \mathrm{mU} / \mathrm{L}$, the FT4 level had decreased to within the normal range on June 16, 2010, when MMI was reduced to $10 \mathrm{mg}$ / day. Thereafter, the patient began to suffer muscle pain and stiffness. She was referred to our hospital on August 2010, when the CK level had increased to 4,719 U/L (CK isozyme; type MM, 98\%; normal, 93-99\%) and thyroid function tests confirmed a state of subclinical hyperthyroidism with a TSH level of $0.05 \mathrm{mU} / \mathrm{L}$ and an FT4 level of $0.82 \mathrm{ng} / \mathrm{dL}$. The $\mathrm{MMI}$ and $\beta$-blocker were discontinued and potassium iodide (KI) administration was begun. 
The CK level decreased to $1,120 \mathrm{U} / \mathrm{L}$ and thyroid function tests confirmed a euthyroid state with a TSH level of $2.56 \mathrm{mU} / \mathrm{L}$ and an FT4 level of $0.78 \mathrm{ng} / \mathrm{dL}$ on September 2010, when KI was exchanged for PTU (100 mg/day). Although CK levels were within the normal range, hyperthyroidism recurred; and PTU was increased gradually to 300 $\mathrm{mg} /$ day on November 2010. Thereafter, she suffered muscle pain again and CK levels were elevated to $521 \mathrm{U} / \mathrm{L}$ (CK isozyme; type MM, 96\%) on January 2011. Although PTU was decreased gradually to $100 \mathrm{mg}$ /day on March 2011, CK levels remained high and thyroid function remained in a state of subclinical hyperthyroidism. PTU was discontinued on April 2011 and serum CK levels decreased to normal, but hyperthyroidism recurred and the patient did not consent to the alteration of treatment from antithyroid drugs to radioiodine therapy or surgical treatment. PTU was restarted and the $\beta$-blocker was exchanged from metoprolol to propranolol on May 2011. PTU was increased gradually from a dose of 50 to $300 \mathrm{mg} /$ day. Serum CK levels did not increase, but hyperthyroidism persisted. After we exchanged PTU for MMI (20 $\mathrm{mg}$ /day) and levothyroxine ( $25 \mu \mathrm{g} /$ day $)$ on November 2011, serum CK levels did not increase and hyperthyroidism improved. Serum concentrations of TSH and FT4 together with the common logarithm of the CK level (log CK) are shown in Figure 1. Informed consent was obtained from the patient.

\section{Discussion}

Serum CK concentration is usually normal in thyrotoxicosis and high in hypothyroidism $[2,10]$. In the present case, the patient experienced myalgia and manifested increased serum CK levels 2 - 4 months after initiation of administration of antithyroid drugs. The possible causes of these events are as follows: collagen disease such as dermatomyositis and polymyositis, inflammatory myopathy, side effect of $\beta$-blockers, muscle disorders associated with thyrotoxicosis, and rapid decrease of thyroid hormone due to the treatment of hyperthyroidism.

Shergy and Caldwell reported a case of polymyositis after PTU treatment [4]. In the present case, there were no dermatological findings specific to dermatomyositis or polymyositis. Anti-ribonucleoprotein antibody and anti-Jo-1 antibody were negative and there were no inflammatory findings. Pindolol, one of the $\beta$-blockers, is known to have a reversible side effect of serum CK elevation [11]. In the present case, serum CK elevation was observed during the administration of metoprolol, but not propranolol. However, there was a period of normal CK levels during the administration of metoprolol - from October 2011 to November 2011. These findings indicate that collagen disease, inflammatory myopathy, and side effects of $\beta$-blockers did not cause the serum CK elevations in the present case.

Muscle disorders such as thyrotoxic myopathy, myas- thenia gravis, and thyrotoxic periodic paralysis are known to occur in some patients with thyrotoxicosis. However, the CK level is normal in thyrotoxic myopathy [10]. In the present case, anti-acetylcholine receptor antibody was negative and there was no electrolyte imbalance, muscle weakness, or periodic paralysis. There have been only 5 reported cases of rhabdomyolysis as a result of thyrotoxicosis [12-16]. In the present case, the CK level was high when the patient visited our hospital for the first time in a state of thyrotoxicosis. However, it decreased to normal with decreases of FT3 and FT4, and further decreased to low levels together with the re-elevation of FT3. The first elevation of the CK levels in March 2010 might have been related to thyrotoxicosis. However, thyroid function was in a state of subclinical hyperthyroidism- not thyrotoxicosis- at the second and third instances of elevated CK levels in August 2010 and from January to April 2011, respectively.

Suzuki et al described 4 cases of adult patients with GD who had abnormal increases in serum CK concentrations during treatment with antithyroid drugs [3]. They speculated that a rapid decrease in thyroid hormones resulted in a local hypothyroid state within the muscle tissue, thereby resulting in CK elevations. They also recommended adding levothyroxine to the regimen rather than discontinuing the antithyroid agents if myalgia, muscle cramps, or elevation of serum CK occur within months of initiation of medical treatment for GD. Previous reports can be divided into 3 categories: (1) 5 cases where adding levothyroxine to MMI decreased serum CK levels [3, 8]; (2) 4 cases where reduction of MMI decreased serum CK levels $[3,5,7,8]$; and (3) 2 miscellaneous cases, one in which treatment was changed from antithyroid drugs to surgical treatment without adding levothyroxine to MMI [9] and the other being a case of exercise-induced CK elevation during treatment with MMI and levothyroxine [6]. We speculated from the clinical course that the present case belonged to the first category.

In conclusion, we described the elevation of serum CK levels during treatment with antithyroid drugs in a patient with GD. A rapid decrease of thyroid hormone might have caused the increased serum concentrations of $\mathrm{CK}$ and muscle symptoms in this patient. Adding levothyroxine to the regimen rather than discontinuing the antithyroid drugs might be effective in these patients.

\section{Conflict of Interest}

The authors have nothing to declare..

\section{References}

1. Cooper DS. Antithyroid drugs. $\mathrm{N}$ Engl $\mathrm{J}$ Med. 2005;352(9):905-917. 
2. Gardner DF. The neuromuscular system and brain in hypothyroidism. In: Braverman LE, Utiger RD, eds. Werner \& Ingbar's the thyroid: a fundamental \& clinical text. 9th ed. Philadelphia: Lippincott Williams \& Wilkins, 2005: 836-841.

3. Suzuki S, Ichikawa K, Nagai M, Mikoshiba M, Mori J, Kaneko A, Sekine R, et al. Elevation of serum creatine kinase during treatment with antithyroid drugs in patients with hyperthyroidism due to Graves disease. A novel side effect of antithyroid drugs. Arch Intern Med. 1997;157(6):693-696.

4. Shergy WJ, Caldwell DS. Polymyositis after propylthiouracil treatment for hyperthyroidism. Ann Rheum Dis. 1988;47(4):340-343.

5. Ueda N, Okahata H, Jinno K, Nishi Y. A case of Basedow disease with myalgia and high serum creatine kinase concentrations during anti-thyroid drug therapy. Nippon Shonika Gakkai Zassi (The Journal of the Japan Pediatric Society). 2000; 104(6): 670-673 (In Japanese).

6. Morisawa Y, Kikuchi H, Okada T, Fujieda M, Hosokawa T, Takechi T, Wakiguchi H. A case of hyperthyroidism accompanied by rhabdomyolysis during antithyroid drug therapy. Shonika (Pediatrics). 2004; 45(9): 16511655 (In Japanese).

7. Kihara M, Yamauchi A, Yokomise H. A case of Graves' disease with myalgia and marked elevation of serum creatine phosphokinase concentrations during antithyroid drug therapy. Naika (Internal Medicine). 2005; 95(1): 177-179 (In Japanese).

8. Mizuno H, Sugiyama Y, Nishi Y, Ueda N, Ohro Y, Togari $\mathrm{H}$. Elevation of serum creatine kinase in response to medical treatment of Graves' disease in children. Acta Paediatr. 2006;95(2):243-245.

9. Ito J. A case of a girl with Graves' disease accompanied by rhabdomyolysis during antithyroid drug therapy. Horumon to Rhinsho (Hormone and Clinical Medicine). 2010; 58 suppl: 79-81 (In Japanese).

10. Gardner DF. The neuromuscular system and brain in thyrotoxicosis. In: Braverman LE, Utiger RD, eds. Werner \& Ingbar's the thyroid: a fundamental \& clinical text 9th ed. Philadelphia: Lippincott Williams \& Wilkins, 2005: 637-643.

11. Tomlinson B, Cruickshank JM, Hayes Y, Renondin JC, Lui JB, Graham BR, Jones A, et al. Selective betaadrenoceptor partial agonist effects of pindolol and xamoterol on skeletal muscle assessed by plasma creatine kinase changes in healthy subjects. Br J Clin Pharmacol. 1990;30(5):665-672.

12. Bennett WR, Huston DP. Rhabdomyolysis in thyroid storm. Am J Med. 1984;77(4):733-735.

13. Hosojima H, Iwasaki R, Miyauchi E, Okada H, Morimoto S. Rhabdomyolysis accompanying thyroid crisis: an autopsy case report. Intern Med. 1992;31(10):1233-1235.

14. Alshanti M, Eledrisi MS, Jones E. Rhabdomyolysis associated with hyperthyroidism. Am J Emerg Med. 2001;19(4):317.

15. Cakir M, Mahsereci E, Altunbas H, Karayalcin U. A case of rhabdomyolysis associated with thyrotoxicosis. J Natl Med Assoc. 2005;97(5):732-734.

16. Lichtstein DM, Arteaga RB. Rhabdomyolysis associated with hyperthyroidism. Am J Med Sci. 2006;332(2):103105 . 